\title{
Taxonomic reassessment of the genus Dichotomius \\ (Coleoptera: Scarabaeinae) through integrative \\ taxonomy (\#35355)
}

Second revision

Guidance from your Editor

Please submit by $\mathbf{3 0}$ Jun $\mathbf{2 0 1 9}$ for the benefit of the authors (and your $\$ 200$ publishing discount).

\section{Structure and Criteria}

Please read the 'Structure and Criteria' page for general guidance.

\section{(2) Custom checks}

Make sure you include the custom checks shown below, in your review.

\section{Raw data check}

르 Review the raw data. Download from the location described by the author.

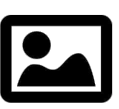

\section{Image check}

Check that figures and images have not been inappropriately manipulated.

Privacy reminder: If uploading an annotated PDF, remove identifiable information to remain anonymous.

\section{Files}

Download and review all files from the materials page.
1 Tracked changes manuscript(s)

1 Rebuttal letter(s)

11 Figure file(s)

4 Table file(s)

1 Raw data file(s)

\section{(? Custom checks}

\section{DNA data checks}

Have you checked the authors data deposition statement?

Can you access the deposited data?

Has the data been deposited correctly?

Is the deposition information noted in the manuscript? 


\section{Structure your review}

The review form is divided into 5 sections. Please consider these when composing your review:

\section{BASIC REPORTING}

2. EXPERIMENTAL DESIGN

3. VALIDITY OF THE FINDINGS

4. General comments

5. Confidential notes to the editor

You can also annotate this PDF and upload it as part of your review

When ready submit online.

\section{Editorial Criteria}

Use these criteria points to structure your review. The full detailed editorial criteria is on your guidance page.

\section{BASIC REPORTING}

Clear, unambiguous, professional English language used throughout.

Intro \& background to show context. Literature well referenced $\&$ relevant.

Structure conforms to Peer] standards, discipline norm, or improved for clarity.

Figures are relevant, high quality, well labelled \& described.

Raw data supplied (see Peer] policy).

\section{EXPERIMENTAL DESIGN}

Original primary research within Scope of the journal.

Research question well defined, relevant \& meaningful. It is stated how the research fills an identified knowledge gap.

Rigorous investigation performed to a high technical \& ethical standard.

Methods described with sufficient detail \& information to replicate.

\section{VALIDITY OF THE FINDINGS}

Impact and novelty not assessed.

Negative/inconclusive results accepted. Meaningful replication encouraged where rationale $\&$ benefit to literature is clearly stated.

All underlying data have been provided; they are robust, statistically sound, $\&$ controlled.
Speculation is welcome, but should be identified as such.

Conclusions are well stated, linked to original research question $\&$ limited to supporting results. 


\section{Standout \\ reviewing tips}

The best reviewers use these techniques

Tip

\section{Support criticisms with evidence from the text or from other sources}

\section{Give specific suggestions on how to improve the manuscript}

\section{Comment on language and grammar issues}

\author{
Please provide constructive \\ criticism, and avoid personal \\ opinions
}

\section{Example}

Smith et al (J of Methodology, 2005, V3, pp 123) have shown that the analysis you use in Lines 241-250 is not the most appropriate for this situation. Please explain why you used this method.

Your introduction needs more detail. I suggest that you improve the description at lines 57- 86 to provide more justification for your study (specifically, you should expand upon the knowledge gap being filled).

The English language should be improved to ensure that an international audience can clearly understand your text. Some examples where the language could be improved include lines 23, 77, 121, 128 - the current phrasing makes comprehension difficult.

1. Your most important issue

2. The next most important item

3....

4. The least important points

I thank you for providing the raw data, however your supplemental files need more descriptive metadata identifiers to be useful to future readers. Although your results are compelling, the data analysis should be improved in the following ways: $A A, B B, C C$

I commend the authors for their extensive data set, compiled over many years of detailed fieldwork. In addition, the manuscript is clearly written in professional, unambiguous language. If there is a weakness, it is in the statistical analysis (as I have noted above) which should be improved upon before Acceptance.
Comment on strengths (as well as weaknesses) of the manuscript 


\title{
Taxonomic reassessment of the genus Dichotomius (Coleoptera: Scarabaeinae) through integrative taxonomy
}

\author{
Carolina Pardo-Diaz ${ }^{\text {Corresp., } 1}{ }^{1}$, Alejandro Lopera Toro ${ }^{2}$, Sergio Andres Peña Tovar ${ }^{3}$, Rodrigo Sarmiento-Garcés ${ }^{4}$, \\ Melissa Sanchez Herrera ${ }^{1}$, Camilo Salazar $^{1}$ \\ ${ }^{1}$ Biology Program, Faculty of Natural Sciences and Mathematics, Universidad del Rosario, Bogota, D.C, Colombia \\ 2 Fundacion Ecotropico, Bogota D.C., Colombia \\ 3 Universidad Distrital Francisco José de Caldas, Bogota, D.C, Colombia \\ 4 Facultad de Ciencias, Universidad Nacional de Colombia, Bogota D.C., Colombia \\ Corresponding Author: Carolina Pardo-Diaz \\ Email address: geimy.pardo@urosario.edu.co
}

Dung beetles of the subfamily Scarabaeinae are widely recognised as important providers of multiple ecosystem services and are currently experiencing revisions that have improved our understanding of higher-level relationships in the subfamily. However, the study of phylogenetic relationships at the level of genus or species is still lagging behind. In this study we investigated the New World beetle genus Dichotomius, one of the richest within the New World Scarabaeinae, using the most comprehensive molecular and morphological dataset for the genus to date (in terms of number of species and individuals). Besides evaluating phylogenetic relationships, we also assessed species delimitation through a novel Bayesian approach (iBPP) that enables morphological and molecular data to be combined. Our findings support the monophyly of the genus Dichotomius but not that of the subgenera Selenocopris and Dichotomius sensu stricto (s.s). Also, our results do not support the recent synonymy of Selenocopris with Luederwaldtinia. Some species-groups within the genus were recovered, and seem associated with elevational distribution. Our species delimitation analyses were largely congruent irrespective of the set of parameters applied, but the most robust results were obtained when molecular and morphological data were combined. Although our current sampling and analyses were not powerful enough to make definite interpretations on the validity of all species evaluated, we can confidently recognise $D$. nisus, $D$. belus and $D$. mamillatus as valid and well differentiated species. Overall, our study provides new insights into the phylogenetic relationships and classification of dung beetles and has broad implications for their systematics and evolutionary analyses. 


\section{Taxonomic reassessment of the genus Dichotomius}

2 (Coleoptera: Scarabaeinae) through integrative

3 taxonomy

4

5 Carolina Pardo-Diaz ${ }^{1}$, Alejandro Lopera Toro ${ }^{2}$, Sergio Andres Peña Tovar ${ }^{3}$, Rodrigo Sarmiento-

6 Garcés $^{4}$, Melissa Sanchez Herrera ${ }^{1}$, Camilo Salazar ${ }^{1}$

7

$8{ }^{1}$ Biology Program, Faculty of Natural Sciences and Mathematics, Universidad del Rosario,

9 Bogota D.C., Colombia

$10{ }^{2}$ Fundacion Ecotropico, Bogota D.C., Colombia

$11{ }^{3}$ Universidad Distrital Francisco José de Caldas, Bogota D.C., Colombia

$12{ }^{4}$ Facultad de Ciencias, Universidad Nacional de Colombia, Bogota D.C., Colombia

13

14

15

16

Corresponding Author:

17 Carolina Pardo-Diaz ${ }^{1}$

18 Cra. 24 No 63C-69, Bogotá D.C. 111221, Colombia

19

20

Email address: geimy.pardo@urosario.edu.co

21

22 


\section{Abstract}

Dung beetles of the subfamily Scarabaeinae are widely recognised as important providers of multiple ecosystem services and are currently experiencing revisions that have improved our

27 understanding of higher-level relationships in the subfamily. However, the study of phylogenetic relationships at the level of genus or species is still lagging behind. In this study we investigated the New World beetle genus Dichotomius, one of the richest within the New World Scarabaeinae, using the most comprehensive molecular and morphological dataset for the genus to date (in terms of number of species and individuals). Besides evaluating phylogenetic relationships, we also assessed species delimitation through a novel Bayesian approach (iBPP) that enables morphological and molecular data to be combined. Our findings support the monophyly of the genus Dichotomius but not that of the subgenera Selenocopris and Dichotomius sensu stricto (s.s). Also, our results do not support the recent synonymy of Selenocopris with Luederwaldtinia. Some species-groups within the genus were recovered, and seem associated with elevational distribution. Our species delimitation analyses were largely congruent irrespective of the set of parameters applied, but the most robust results were obtained when molecular and morphological data were combined. Although our current sampling and analyses were not powerful enough to make definite interpretations on the validity of all species evaluated, we can confidently recognise $D$. nisus, $D$.

1 belus and D. mamillatus as valid and well differentiated species. Overall, our study provides new insights into the phylogenetic relationships and classification of dung beetles and has broad implications for their systematics and evolutionary analyses. 


\section{Introduction}

46 Scarabaeinae dung beetles are one of the most morphologically diverse groups of animals

47 (Philips 2011) comprising more than 6000 species and 200 genera worldwide (Tarasov \& Génier 48 2015). Within this dung-feeding subfamily, Dichotomius Hope, 1838 constitutes one of the richest genera endemic to the Americas, with 171 described species (Schoolmeesters 2019). Compared to other regions, its diversity is highest in South America where more than 100 species can be found (Bohórquez \& Montoya 2009; Vulinec 1999). Species in this genus vary in size (5-38 mm), show strong sexual dimorphism and have colours usually ranging from dark brown to black (Nunes 2017; Sarmiento-Garcés \& Amat-García 2014; Vaz-de-Mello et al. 2011). Furthermore, Dichotomius species are typically nocturnal, more abundant in the rainy season and prevalent in several Neotropical terrestrial habitats where they play multiple ecological roles (López-Guerrero 2005; Maldaner et al. 2015; Vulinec 1999). For example, they promote bioturbation, remove faeces from forests and pastures, bury seeds, stimulate seed germination and even act as intermediate hosts of swine parasites (Almeida et al. 2014; Nichols et al. 2008; Vulinec 1999).

The taxonomy of these beetles, which is entirely based on morphological characters, is still not sufficiently resolved despite them being ubiquitous and ecologically relevant. The genus was divided into four subgenera by Luederwaldt (1929): Dichotomius sensu stricto (s.s.), Selenocopris, Homocanthonides and Cephagonus (Luederwaldt 1929). Since then there have been few changes, the most relevant done by Martinez (1951) that keeps Dichotomius s.s. and Homocanthonides, but changes Selenocopris to Luederwaldtinia and Cephagonus to Selenocopris (Martínez 1951). The most recent revision of the genus Dichotomius differentiates

the four subgenera based mainly on variations of the clypeo-genal angle (Nunes 2017) 
68 supporting the initial division by Luederwaldt in 1921: Dichotomius s.s. (70 spp);

69 Homocanthonides (1 spp); Cephagonus (16 spp) and Selenocopris (75 spp), synonymising the

70 latter with Luederwaldtinia. These subgenera are further divided into species groups, each one 71 containing multiple species (Luederwaldt 1929; Martínez 1951; Nunes 2017; Nunes \& Vaz-de-

72 Mello 2013; Nunes \& Vaz-de-Mello 2016). Although there has been a recent interest in revising

73 these subgenera and species groups, their definition is still problematic due to relying on

74 morphological traits alone (Maldaner et al. 2015; Nunes 2017; Nunes \& Vaz-de-Mello 2013;

75 Nunes \& Vaz-de-Mello 2016). This problem also applies to species delimitation in the genus

76 because some species such as Dichotomius satanas display a spectacular range of morphological

77 variability, which suggests the possibility of distinct species being misclassified as a single one

78 (Sarmiento-Garcés \& Amat-García 2014). In fact, some authors consider D. satanas as a species

79 complex in need of revision (Nunes 2017). For example, specimens of D. satanas from Central

80 America have been reported to look different from those from Colombia (with the type being

81 from this country), and within Colombia, females of D. satanas from the Eastern Cordillera have

82 two or four protuberances on the pronotum while females from the Western and Central

83 cordillera have only two (Fig. S1) (Sarmiento-Garcés \& Amat-García 2014).

84 The use of molecular tools constitutes an alternative to accurately delimit and identify

85 taxa that lack useful morphological characters (Dayrat 2005; Dupuis et al. 2012; Schlick-Steiner

86 et al. 2009; Schwarzfeld \& Sperling 2014). This approach has been primarily used in

87 Scarabaeinae beetles to resolve deep relationships (Gunter et al. 2016; Tarasov \& Génier 2015),

88 however, the relationships at the genus or species level in this subfamily remains understudied.

89 For this reason, there is currently no molecular phylogeny available for Dichotomius. Recent

90 studies on deep phylogenies for Coleoptera and dung beetles, however, indicate that the genus is 
91 likely paraphyletic (although this result is based on a small number of species of Dichotomius

92 and only one individual per species) (Bocak et al. 2014; Monaghan et al. 2007).

93 In recent years taxonomists have begun to integrate different lines of evidence to discover

94 and delimit species, which is often referred to as "integrative taxonomy" (Padial \& De La Riva

95 2010; Schlick-Steiner et al. 2009). The application of this approach, usually done through the

96 combination of molecular and morphological information, has improved taxonomic rigor

97 yielding a more precise biodiversity inventory (both reducing or increasing species numbers)

98 (Sturaro et al. 2018). In this study we implemented an integrative taxonomy approach that

99 combines morphological and molecular data (both mitochondrial and nuclear) to make a

100 preliminary assessment of the species diversity and phylogenetic relationships in the genus

101 Dichotomius. The information derived from this research is crucial to further characterise

102 species' richness as well as to understand patterns of adaptation, speciation and biogeography in

103 these dung beetles.

104

105

106

107 Sampling

108 Our total sample set consisted of 304 individuals of Dichotomius (31 species). The

109 morphological analysis of male genitalia included 208 individuals from 28 species (Table S1),

110 whereas the genetic analysis consisted of 145 specimens from 16 species; 52 of these sequences

111 were obtained from GenBank (Table S1). This is representative of 14 species-groups and three

112 subgenera in Dichotomius. All specimens for which we obtained data (DNA or morphology)

113 came from the following biological collections: (i) Colección Alejandro Lopera-Toro (CALT-

114 ECC, Colombian Collection ID 2), (ii) Museo de Historia Natural Universidad Distrital (MUD, 
115 Colombian Collection ID 46), and (iii) Colección de Artrópodos de la Universidad del Rosario

116 (CAUR, Colombian Collection ID 229). These individuals were identified by experts or using

117 most recent taxonomical keys (Nunes 2017; Sarmiento-Garcés \& Amat-García 2014; Vaz-de-

118 Mello et al. 2011).

119

120 Morphometric analyses

121 Because shape of the male genitalia is considered one of the most informative morphological

122 characters in the classification of Dichotomius species (López-Guerrero 2005; Sarmiento-Garcés

$123 \&$ Amat-García 2014), we analysed the quantitative variation of the aedeagus in 208 individuals

124 (28 species; Table S1). Male genitalia preparation followed a standard procedure: we detached

125 the last two abdominal segments, soaked them in $10 \% \mathrm{KOH}$ at $60^{\circ} \mathrm{C}-70^{\circ} \mathrm{C}$ for 12 hours and

126 neutralized them in 1\% acetic acid to finally store them in glycerine (Sarmiento-Garcés \& Amat-

127 García 2014). Then, we cleaned and dissected the aedeagus. Finally, we photographed the

128 aedeagus in dorsal view and using a Leica DFC320 digital camera coupled to a Leica S6

129 stereoscope at $4 \mathrm{X}$ magnification.

130 We applied landmark-based geometric morphometrics to these photographs in order to

131 analyse genital shape. We used tpsDig v.2.31 (Rohlf 2004) to digitise 33 landmarks per

132 individual that describe the outline of the aedeagus, all of them were placed on the parameres

133 (Fig. S2a). This landmark dataset was subjected to superimposition using a Generalized

134 Procrustes Analysis (GPA) in the R package 'geomorph' (Adams \& Otárola-Castillo 2013). For

135 this, the software aligns, scales and rotates the configurations to line up the corresponding

136 landmarks as closely as possible, minimizing differences between landmark configurations

137 without altering shape. Then, we obtained partial warps (or shape variables) that indicate partial

Peer] reviewing PDF | (2019:02:35355:2:1:NEW 18 Jun 2019) 
138 contributions of hierarchically scaled vectors spanning a linear shaped space. With this

139 information we generated a consensus shape that summarises the aedeagus' shape variation

140 among all Dichotomius species included (Fig. S3). In this way, each specimen's shape is

141 quantified by the deviation of its landmark configuration from the average landmark

142 configuration (i.e. consensus shape), which allows to visualise differences between groups.

143 Differences in aedeagus' shape among species were tested using a Procrustes MANOVA applied

144 to the aligned landmark configurations. This was done using the procD.lm function in the

145 'geomorph' R package (Adams \& Otárola-Castillo 2013).

146 We implemented a principal component analysis (PCA) on the procrustes aligned data

147 using the plotTangentSpace function in the 'geomorph' R package (Adams \& Otárola-Castillo

148 2013). Of the 66 PCs produced, the first two cumulatively accounted for $\sim 92 \%$ of the total shape

149 variance; therefore, further analyses were performed on these PCs. We used the function

150 plotRefToTarget from the same package to generate the deformation grids representing the

151 extremes (maximum and minimum) of shape variation along the principal components 1 and 2

152 (PC1 and PC2). We then applied a discriminant analysis of principal components (DAPC) using

153 the R package 'adegenet' (Jombart 2008).

154 We also applied a model-based hierarchical clustering using the R package 'mclust'

155 (Scrucca et al. 2016) in order to identify groups of individuals that resemble each other,

156 independent of other evidence or a priori assignments. This method uses expectation

157 maximization (EM) to estimate the Maximum Likelihood (ML) of alternative multivariate

158 mixture models that describe shape variation in the data and estimates the optimal number of

159 clusters based on the Bayesian Information Criterion (BIC). All models were evaluated for a 
160 predefined number of 1 to the maximum number of morphospecies studied ( 28 in our case, i.e.

161 those for which morphology data was available).

162

163 Molecular analyses

164 We extracted DNA from legs of 95 specimens of Dichotomius using the DNeasy Blood \& Tissue

165 Kit (QIAGEN) following the manufacturer's instructions with minor modifications: $40 \mu \mathrm{L}$ of 166 proteinase $\mathrm{K}$ were used, protein digestion lasted for at least 2 hours and the final elution was 167 made in $100 \mu \mathrm{L}$ of warm AE buffer. Then, we amplified the 3' and 5' ends of the cytochrome c 168 oxidase I gene (COI), and the nuclear gene 28S. All PCR reactions were performed in a final 169 volume of $10 \mu \mathrm{L}$ containing $1 \mu \mathrm{L}$ of $10 \mathrm{X}$ Buffer, $0.6 \mu \mathrm{L}$ of $\mathrm{MgCl}_{2}(25 \mathrm{mM}), 0.5 \mu \mathrm{L}$ of dNTP mix

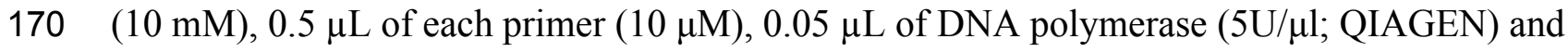
$1715.85 \mu \mathrm{L}$ of $\mathrm{dH}_{2} \mathrm{O}$. To amplify the 3' end of the COI gene we used the primers C1-J-2183 (Jerry: 172 5'-CAACATTTATTTTGATTTTTTGG-3') and TL2-N-3014 (Pat: 5'-

173 TCCAATGCACTAATCTGCCATATTA-3') (Simon et al. 1994). The amplification PCR profile 174 consisted of an initial denaturation step of $94^{\circ} \mathrm{C}$ for 5 minutes, 7 cycles of denaturation at $94^{\circ} \mathrm{C}$ 175 for 1 minute, annealing at $48^{\circ} \mathrm{C}$ for 45 seconds and extension at $72^{\circ} \mathrm{C}$ for 1 minute, followed by 17633 cycles of denaturation at $94^{\circ} \mathrm{C}$ for 45 seconds, annealing at $52^{\circ} \mathrm{C}$ for 45 seconds and extension 177 at $72^{\circ} \mathrm{C}$ for 1.5 minutes, with a final extension at $72{ }^{\circ} \mathrm{C}$ for 10 minutes. The 5 ' end of the COI 178 gene (the barcode) was amplified with the primers LCO1490 (5'-

179 GGTCAACAAATCATAAAGATATTGG -3') and HCO2198 (5'-

180 TAAACTTCAGGGTGACCAAAAAATCA -3') (Folmer et al. 1994), using the following PCR 181 conditions: $94^{\circ} \mathrm{C}$ for 5 minutes, 35 cycles of $94^{\circ} \mathrm{C}$ for 30 seconds, $45^{\circ} \mathrm{C}$ for 30 seconds, $72^{\circ} \mathrm{C}$ for 1821.5 minutes and a final extension at $72^{\circ} \mathrm{C}$ for 7 minutes. To amplify the $28 \mathrm{~S}$ gene we used the 
183 primers 28SFF (5'-TTACACACTCCTTAGCGGAT-3') and 28SDD (5'-

184 GGGACCCGTCTTGAAACAC-3') (Monaghan et al. 2007). PCR cycling was $94^{\circ} \mathrm{C}$ for 5

185 minutes, 38 cycles of $94^{\circ} \mathrm{C}$ for 30 seconds, $53^{\circ} \mathrm{C}$ for 30 seconds, $72^{\circ} \mathrm{C}$ for 45 seconds and a final 186 extension of $72^{\circ} \mathrm{C}$ for 10 minutes.

All PCR products were purified with ExoSAP and their bidirectional sequencing was carried out by ELIM Biopharmaceuticals Inc. (Hayward, CA). Forward and reverse sequences 189 from each amplicon were verified and assembled into a single consensus contig based on a minimum match of $80 \%$ and a minimum overlap of $50 \mathrm{bp}$ using CLC main workbench. 2004) in MESQUITE v3.04 (Maddison \& Maddison 2011); poorly aligned regions were corrected manually. Protein coding sequences were translated into amino acids to confirm the absence of stop codons and anomalous residues in MESQUITE v3.04 (Maddison \& Maddison 2011). Additional sequences of Dichotomius available in GenBank (Table S1) were downloaded and integrated into the alignments. All sequences generated by us were deposited in GenBank and their accession numbers are listed in Table S1. and 16S. All sequences from the latter marker were obtained from GenBank and correspond to the species D. nisus, D. yucatanus, D. parcepunctatus and D. boreus (Table S1). We and nine outgroups: Deltochilum larseni, Neateuchus proboscideus, Ontherus diabolicus,

204 Pleurophorus caesus (Table S1). We calculated a ML tree using IQ-TREE using the entire 205 haplotype set derived from all species and individuals (Nguyen et al. 2015) with 1,000 ultrafast 
206 bootstrap replicates. This was done based on the substitution model showing the smallest AIC

207 score for each partition (i.e. COI, 28S and 16S), which was also selected using IQ-TREE

208 ((Nguyen et al. 2015); Table S2).

209 To test whether D. satanas exhibits genetic clustering associated to the Colombian

210 Cordilleras of the Andes as previously suggested (Sarmiento-Garcés \& Amat-García 2014), we

211 also estimated a ML topology using all sequences available for the Colombian specimens of this

212 species (COI and 28S) and using the conditions aforementioned. The sequences were all

213 concatenated into a single alignment of $2,145 \mathrm{bp}$ that included one individual of $D$. boreus, $D$.

214 quinquelobatus and $D$. protectus (outgroups) and 60 individuals of $D$. satanas: 8 from the

215 Central Cordillera of Colombia, 14 from the West Cordillera of Colombia and 38 from the East

216 Cordillera of Colombia.

217 Finally, we used DnaSP version 6.12.01 (Rozas et al. 2003) to calculate diversity

218 parameters (i.e. number of haplotypes $(\mathrm{H})$, haplotype diversity, genetic diversity ( $\pi$ and $\theta$ ) and

219 Tajima's D) for all species and for D. satanas, as well as summary statistics of population

220 differentiation among populations of $D$. satanas.

221

\section{Species delimitation analyses}

223 We implemented a joint Bayesian inference based on genetic and phenotypic data to delimit

224 species using iBPP (Solís-Lemus et al. 2014). This was done using two independent data sets: (i)

225 all species, and (ii) D. satanas from Colombia only. In both cases, we ran the program for three

226 different datasets: (i) morphological and molecular data combined, (ii) morphological data alone,

227 (iii) molecular data alone. In all cases, we used the species-tree topology from IQ-tree as the

228 guide tree. The morphological character matrix used as input included the values of PC1 and 
229 PC2 from the geometric morphometric analyses. The molecular matrix included all sequences 230 available for the markers COI, $16 \mathrm{~S}$ and $28 \mathrm{~S}$. We specified nine combinations of the prior 231 distribution for the ancestral population size $(\theta)$ and the root age of the tree $(\tau)$ ranging from 232 scenarios that represent large population sizes and a deep divergence time $(\theta=\mathrm{G}(1,10)$ and $\tau$ $233=\mathrm{G}(1,10))$ to those representing small population sizes and a shallow divergence time $(\theta=\mathrm{G}(2$, $2342000)$ and $\tau=\mathrm{G}(2,2000))$ as previously used (Eberle et al. 2016; Olave et al. 2017). We used 235 default values of $\sigma^{2}$ and $\kappa=0$, thus these priors are non-informative and the program estimates 236 them. The MCMC analysis was run over 50,000 generations, sampling every 1,000 steps and 237 using a $10 \%$ burn-in. We confirmed the robustness of the results by running the analysis with 238 both the algorithms 0 and 1 for rjMCMC searches. As results were very similar, we present those of algorithm 1. The parameters of the locus-specific rates of evolution were fine-tuned using an 240 auto option.

\section{Results}

243

244 Morphological analyses

245 When we tested for aedeagus shape variation in the entire Procrustes shape space, we found 246 differences among all categories tested (i.e. subgenera, species-groups and species; Procrustes MANOVA $p<0.001$ in all cases). The PCA of the aedeagus shape revealed that most of its variation is contained in few dimensions. The first two PCs accounting for $91.9 \%$ of the total variance. $\mathrm{PC} 1$ explained $84.16 \%$ of the aedeagus shape and was driven by the width of the lateral 
253 existence of four discrete genitalia morphology groups within Dichotomius (Fig. 1b and Fig. S4).

254 The first group (depicted in red tones) was composed mostly by members of the subgenus

255 Selenocopris sensu (Nunes 2017) from the species-groups Agenor, Batesi and Inachus (i.e. $D$.

256 agenor, D. batesi, D. belus, D. deyrollei, D. favi, D. fortestriatus, and D. yucatanus). This group

257 also contained individuals of the subgenus Dichotomius s.s., exclusively those in the species-

258 group Carolinus (i.e. D. amicitiae and D. coenosus). Finally, the species D. fonsecae (subgenus

259 Cephagonus, species group Fissus) also clustered in this first group. The second group (depicted

260 in green tones) was mainly formed by species that belong to the subgenus Dichotomius s.s. from

261 the species-groups Boreus, Buqueti and Mamillatus (i.e. D. boreus, D. compresicollis, $D$.

262 mamillatus, D. podalirius, D. riberoi and D. robustus); the species D. inachoides (subgenus

263 Selenocopris, species-group Agenor) also grouped here. The third group (yellow) consisted

264 exclusively of individuals from D. nisus (isolated species in the Selenocopris subgenus sensu

265 Nunes 2017. The fourth group comprised only species from the subgenus Dichotomius s.s.,

266 species-group Mormon, namely: D. alyattes, D. andresi, D. ohausi, D. protectus, D. divergens,

267 D. quinquelobatus, D. quinquedens and D. satanas (blue tones). Although the species $D$.

268 costaricensis and D. worontzowi (both of the Dichotomius s.s. subgenus) appeared well

269 differentiated from any other species or group, we only have one sample for each of them,

270 preventing us from making strong inferences. Consistently, mclust identified four clusters

271 entirely coincident with the groupings obtained above (Fig. 1c). This variation is best explained

272 by a model with 'diagonal distribution, variable volume and equal shape' (VEI; BIC=1152.184).

273 In summary, variation in genitalia morphology is not entirely consistent with the current

274 taxonomy of Dichotomius (Nunes 2017). Specifically, D. (Selenocopris) nisus (yellow) appears

275 as different from other species in the subgenus Selenocopris (red). Also, species in the Carolinus 
276 group (D. amicitiae and D. coenosus), currently classified as members of Dichotomius s.s., 277 cluster with species from the subgenus Selenocopris (red). Species in the subgenus Dichotomius 278 s.s. formed two clusters, one that contains lowland species (green) and the other composed only 279 by highland Andean species (blue).

280

281 Molecular analyses

282 We found Dichotomius as a monophyletic genus with two well-supported deep clades (Fig. 2, 283 Fig S5). The first clade contains D. (Selenocopris) nisus sister to species from the subgenus 284 Dichotomius s.s. The second clade is composed of species from the Selenocopris subgenus, 285 except for D. carolinus, which is currently included within Dichotomius s.s. Within the first 286 clade (1 in Fig. 2), all species that belong to Dichotomius s.s. were grouped by species-group, 287 with the Mormon, Boreus and Mamillatus groups forming each a monophyletic cluster (Fig. 2; 288 Fig S5). Within each of these species-groups most species appeared as monophyletic, except for 289 D. satanas. This species formed two monophyletic clades, one consisting of Colombian 290 specimens and the other composed by Central American individuals (Fig. 2; Fig S5).Within the 291 second monophyletic clade (2 in Fig. 2) we could not test the monophyly of the species groups 292 due to low species sampling, yet we observed the Agenor species-group as paraphyletic (Fig. 2;

293 Fig S5). In general, mtDNA showed higher haplotype diversity than the 28S nuclear gene (Table 294 1).

295 When populations of $D$. satanas from Colombia were analysed separately to evaluate 296 whether this species displays genetic clustering associated with geography or phenotype 297 (Sarmiento-Garcés \& Amat-García 2014), we mainly observed clustering and genetic 298 differentiation associated to the three Cordilleras of the north of the Andes (Fig. 3, Table 2). 
299 Individuals from the Central and the Western Cordilleras were reciprocally monophyletic, and

300 both were sister to the Western Cordillera clade. Interestingly, this phylogenetic pattern

301 associates to morphological differences in the females: the Central and Western clusters contain

302 females with only two protuberances in the pronotum, while the cluster of the Eastern Cordillera

303 includes females with two and four protuberances. At the same time, the latter cluster separates

304 into two inner groups, one that contains only females with four protuberances and the second, 305 where females of two and four protuberances are found (Fig. 3).

306

307 Species delimitation

308 The total-evidence (morphology and DNA) approach to Bayesian species delimitation (iBPP) did 309 not support the a priori morphospecies assignment (Fig. 4). In most $\theta$ and $\tau$ scenarios tested, the 310 posterior probability for the existence of the 16 morphospecies evaluated was lower than $50 \%$.

311 The only a priori defined species that consistently presented high support for all prior

312 combinations were $D$. belus, D. nisus and D. mamillatus. Other species were supported only

313 when modelling small population sizes $(\theta=0.01)$ and medium to deep divergence time $(\tau=0.05$

314 and $\tau=0.1)$, but never when modelling a shallow divergence time $(\tau=0.01 ;$ Fig. 4$)$.

315 The existence of two deep clades was strongly supported, regardless of the $\theta$ and $\tau$ priors

316 used (1 and 2 in Fig. 4). In the first clade, the existence of species groups Nisus, Mamillatus,

317 Boreus and Mormon was also stronly supported (Fig. 4). In the latter group, the separation of $D$.

318 quinquelobatus from other members of this group showed high posterior probability values in

319 most scenarios, except for those with $\tau=0.01$. However, the separation of $D$. protectus from $D$.

320 andresi, or Colombian D. satanas from D. alyattes was rarely supported (Fig. 4). This was also 
321 observed in the Boreus species-group, where the delimitation between $D$. boreus and $D$.

322 podalirius always had low posterior probabilities (Fig. 4).

323 In the second clade the only well supported species across all the parameter combinations

$324(\theta$ and $\tau)$ was $D$. belus. The later suggest that this species may not be part of the Agenor species

325 group. In contrast, species within the clade sister to D. belus showed very low support in most of

326 the parameter space (Fig. 4). The species delimitation based on molecular or morphological data

327 alone were consistent with the total-evidence approach (Fig. S6). However, the results of these

328 independent data types tended to provide stronger supports to species-groups and some species, 329 especially the molecular data.

330 Finally, the total-evidence analysis of species delimitation done in D. satanas failed to

331 identify any of the phylogenetic clusters associated to geography as separate species (in most $\theta$

332 and $\tau$ scenarios tested the support for these clusters was lower than $60 \%$, Fig. S7a). This suggests

333 that $D$. satanas is likely a single species with phenotypic polymorphism. However, just as before,

334 the analyses with only molecular data presented stronger supports while the analysis based on

335 morphological data provided very poor support Fig. S7b and c).

336

337 Discussion

338 Since the first description of Dichotomius by Hope in 1838 (Hope 1838) about 170 species have

339 been described in the genus using morphology as the only diagnostic tool, and although there

340 have been recent morphological revisions, Dichotomius remains a challenging taxonomic puzzle

341 (Nunes 2017; Nunes \& Vaz-de-Mello 2013; Nunes \& Vaz-de-Mello 2016; Nunes et al. 2012).

342 Here we used aedeagus morphology and phylogenetic analyses to assess the validity of some

343 species in this dung beetle genus. Our study suggests it is necessary to make a comprehensive 
344 revision of the number of species within the genus that combines molecular and morphological 345 data, as well as a broader taxonomic and geographic sampling.

Despite what previous deep phylogenies of the subfamily Scarabaeinae had suggested

347 (Bocak et al. 2014; Monaghan et al. 2007), we found Dichotomius as a monophyletic genus. This

348 is likely because our study is the first to include a more extensive sampling of species and

349 individuals in this genus. We also showed that the subgenera Dichotomius s.s. and Selenocopris

350 previously established by morphology (Nunes 2017) were not supported. Regardless of the non-

351 validity of these subgenera, our data recovered two well supported monophyletic clades

352 consistent with distributional patterns, where species in clade one occur in both Central and

353 South America, and species in clade two are restricted to South America with only one

354 exception: D. satanas (Fig. 2).

355

The position of D. nisus outside Selenocopris and the inclusion of the Carolinus group

356 inside this subgenus causes the non-monophyly of Dichotomius s.s. and Selenocopris. Until

357 recently, D. nisus was recognised as the type species for the Luederwaldtinia subgenus (Martínez

358 1951) but because both Luederwaldtinia and Selenocopris subgenera include described species

359 that have clypeal teeth but lack clypeo-genal angle, Nunes synonymised Luederwaldtinia with

360 Selenocopris (Nunes 2017). Even so, Nunes still recognised D. nisus as unique within

361 Selenocopris, leading to its classification in a separate species-group as an "isolated species"

362 (Nunes 2017; Nunes \& Vaz-de-Mello 2013). However, our data does not agree with this

363 synonymisation as neither the aedeagus morphology nor the molecular data support the placing

364 of D. nisus within Selenocopris and, in fact, both data types show this species more closely

365 related to members of Dichotomius s.s. Also, D. nisus has a unique distribution and ecology that

366 differentiates it from other Dichotomius, being a common species that is restricted to Orinoquia 
367 lowlands, pastures and open environments (França et al. 2016; Louzada \& Carvalho E Silva 368 2009). Therefore, the resurrection of Luederwaldtinia with D. nisus as type species or its 369 inclusion within Dichotomius s.s. needs to be evaluated by studying the morphology and DNA 370 variation of all the species classified under both subgenera. On the other hand, the inclusion of 371 the Carolinus species-group as part of Selenocopris would make this subgenus monophyletic, 372 and makes sense in the light of geographic distribution, since the Carolinus species-group is 373 restricted to Central America (where Dichotomius s.s. does not usually occur). not monophyletic since the molecular phylogeny and the total-evidence delimitation analysis strongly supported the exclusion of $D$. belus from it (Fig. 2). This separation may reflect

377 differences in ecology or distribution of D. belus from the other members of the Agenor species378 group. For instance, while all these species occur in xerophytic forests, D. belus is the only of 379 them that can reach elevations up to 2200 masl (Arellano et al. 2008; Giraldo et al. 2018). This 380 suggests that elevation and/or humidity variables may have contributed to the differentiation of D. belus, possibly acting as a barrier between this species and other lowland species in the Agenor group. In addition, $D$. belus falls much less frequently in pitfall traps compared to $D$. agenor, even though it is abundant when manually collected in cattle dung pads; this may

384 indicate the existence of differences in behaviour or at least in food preferences.

We recovered $D$. yucatanus and $D$. parcepunctatus as sister lineages but the totalevidence species delimitation analysis failed to recognise them as different species despite they belonging to different species-groups (Inachus and Batesi) and having a very distinct geographic distribution. This finding is consistent with a previous molecular phylogeny built for the tribe

Scarabaeidae that recovered D. yucatanus and D. parcepunctatus as sister species across all the 
390 391 392

9008 ML trees sampled (Borrow 2011). Unfortunately, the existing sampling and information on these species is insufficient to explain this pattern and more studies about the ecology and/or distribution of these species are needed.

Our data strongly supported the existence of the species-groups Mamillatus, Mormon and Boreus, and overall, this grouping coincides with differences in elevational distribution. For example, aedeagus morphology grouped the species-groups Mamillatus and Boreus in a single cluster that contains only lowland species with Amazonian distribution (green in Fig. 1), while the Mormon group is composed only by highland species restricted to the Andes (blue in Fig. 1). The molecular phylogeny separated the lowland species in the corresponding Mamillatus and Boreus groups, but these were not reciprocally monophyletic since the Boreus group is more closely related to the highland species. Although $D$. podalirius and $D$. boreus showed phylogenetic divergence (Fig. 2), which can be partially explained by the ability of $D$. boreus to reach higher elevations (100-1000 masl) than D. podalirius (100-350 msal) in the foothills of the Eastern Cordillera of Colombia (Medina et al. 2001), the total-evidence species delimitation failed to recover them as independent species, which may suggest they are different populations of a single species.

Species in the Mormon species-group clustered all together and were hardly distinguishable at the molecular level. Even so, D. satanas split in two monophyletic clusters that correspond to Central American and Colombian individuals, suggesting they are different entities. Nonetheless, the species delimitation method applied was not able to discriminate these taxa as independent (except for D. quinquelobatus). Interestingly, while all species in the Mormon group are found in elevations between 1000 and 2000 masl, only D. quinquelobatus goes down and reaches the foothills of the Eastern Colombia Cordillera (120-2200 masl 
413 (Sarmiento-Garcés \& Amat-García 2014)), thus receiving some influence from the Orinoquia

414 and Amazonia. Our phylogeny suggests that the highland clade derives from lowland species,

415 although this needs further confirmation.

$416 \quad$ Additionally, while Colombian D. satanas showed population structure associated with

417 the Andean Cordilleras, and under morphological based taxonomic studies these populations

418 would be identified as two species, none of our delimitation analyses discriminated these

419 populations as separate entities. Therefore, the currently available data indicates that Colombian

420 D. satanas is a single species that displays a remarkable phenotypic variation in the number of

421 protuberances (two and four) on the pronotum of females. This is a unique condition in the

422 Scarabaeinae subfamily, and this variation is associated with geography to some extent. At

423 present it is not possible to pinpoint the factors contributing to the maintenance of this variation

424 although processes such as sexual selection, known to drive horn polymorphism in multiple

425 species of beetles (Emlen et al. 2007; Kijimoto et al. 2013; Simmons \& Watson 2010), may be

426 implicated. Also, the fact that the four-protuberances morph is collected only in open and

427 disturbed habitats whilst the two-protuberances morph is mostly found in forested habitats

428 suggests that variables such as temperature variation, vegetation coverage and/or food

429 availability, that drastically differ between the two habitats, may be promoting the differentiation

430 between these morphs, at least in females.

431 In general, the results of our total-evidence species delimitation analyses under different

432 scenarios of population size and divergence time were remarkably congruent. However, when

433 the delimitation analysis was based on molecular or morphological data alone the results were

434 much more sensitive to the priors used, either supporting most the a priori morphospecies

435 assignments (molecular data) or almost none at all (morphology data). This pattern has been 
436 previously observed in other studies of species delimitation in beetles, where only the

437 combination of morphological and molecular data resulted in robust estimates by reducing the 438 sensitivity to prior parameter choice (Eberle et al. 2016). Our current sampling (in terms of taxa 439 and genes) does not permit us to make definite interpretations on the validity of all species of 440 Dichotomius, but we can confidently recognise D. nisus, D. belus and D. mamillatus as valid and 441 well differentiated species. Although it would have been ideal to reach a final conclusion for all 442 species evaluated here, species delimitation methods are extremely sensitive to multiple biases 443 such as insufficient or unbalanced sampling, incomplete lineage sorting, population structure 444 and/or hybridisation (Astrin et al. 2012; Carstens et al. 2013; Meyer \& Paulay 2005; Petit \& 445 Excoffier 2009; Sukumaran \& Knowles 2017). In our study, we used the morphology of male 446 genitalia as diagnostic trait but other traits used for the identification of Dichotomius (Nunes 447 2017) need to be considered. Also, we had an unbalanced representation of species in our 448 dataset, which also needs to be corrected in future studies. Despite these limitations, this is the 449 first time an integrative species delimitation approach is implemented in Dichotomius and we 450 feel that our analytical procedures were adequate enough to reveal the ambiguous taxonomic 451 position of several taxa.

Altogether, our findings indicate the need to revise the current taxonomic classification of 453 Dichotomius in the light of both morphological and molecular data. Only such an integrative 454 approach will allow a comprehensive characterisation of the diversity, ecology and distribution 455 of species in this genus, to ultimately understand the mechanisms and processes involved in their 456 adaptation, diversification and speciation.

457

458 Conclusions 
459 Dichotomius is a rich and diverse dung beetle genus (Nunes \& Vaz-de-Mello 2016) that belongs

460 to the tribe Dichotomini, one of the most problematic tribes in Scarabaeinae (Tarasov \&

461 Dimitrov 2016). Therefore, the validation of its taxonomy and evolutionary relations constitutes

462 a step towards a reassessment of the systematic and phylogenetics of New World dung beetles as

463 a whole. Our implementation of a total-evidence species delimitation approach that integrates

464 genetic and phenotypic information provided a powerful tool to accurately delineate lineages in

465 Dichotomius and suggest the existence of fewer species in the genus. We recommend including

466 additional species as well as to sample more loci and phenotypic traits to further improve the

467 taxonomy and biogeography of Dichotomius. However, we highlight the importance of our

468 findings in the understanding of the biogeographical and evolutionary processes influencing this

469 genus, as well as their significance for taxonomy and conservation.

470

471 Acknowledgements

472

473 We would like to thank Rodrigo Sarmiento and Santiago Montoya for helping with the

474 identification of some species and providing valuable opinions. We also thank Camila Ruiz for

475 her help processing some samples of D. satanas. All specimens used came from the following

476 collections: CALT-ECC (Colombian Collection ID 2), MUD (Colombian Collection ID 46), and

477 CAUR (Colombian Collection ID 229).

478

479 References

480

481

482

483

484

485

486
Adams DC, and Otárola-Castillo E. 2013. geomorph: an R package for the collection and analysis of geometric morphometric shape data. Methods Ecol Evol 4:393-399. doi: 310.1111/2041-1210X.12035.

Almeida S, Sperber C, Souza-Ferreira R, and Louzada J. 2014. Does the use of Ivermectin in livestock affects the ecological functions performed by dung beetles? In: XRLd S, editor. Reunión Latinoamericana de Scarabaeoidología. Bogotá, Colombia: Universidad Nacional de Colombia. p 127. 
487

488

489

490

491

492

493

494

495

496

497

498

499

500

501

502

503

504

505

506

507

508

509

510

511

512

513

514

515

516

517

518

519

520

521

522

523

524

525

526

527

528

529

530

531

532
Arellano L, León-Cortés J, and Halffter G. 2008. Response of dung beetle assemblages to landscape structure in remnant natural and modified habitats in southern Mexico. Insect Conservation and Diversity 1:253-262. doi: 210.1111/j.1752-4598.2008.00033.x. 10.1111/j.1752-4598.2008.00033.x

Astrin JJ, Stüben PE, Misof B, Wägele JW, Gimnich F, Raupach MJ, and Ahrens D. 2012. Exploring diversity in cryptorhynchine weevils (Coleoptera) using distance, character, and tree-based species delineation. Molecular Phylogenetics and Evolution 63:1-14. doi: 10.1016/j.ympev.2011.1011.1018. https://doi.org/10.1016/j.ympev.2011.11.018

Bocak L, Barton C, Crampton-Platt A, Chesters D, Ahrens D, and Vogler AP. 2014. Building the Coleoptera tree-of-life for $>8000$ species: composition of public DNA data and fit with Linnaean classification. Systematic Entomology 39:97-110. 10.1111/syen.12037

Bohórquez J, and Montoya J. 2009. Abundancia y preferencia trófica de Dichotomius belus (Coleoptera: Scarabaeidae) en la Reserva Forestal de Colosó, Sucre. . Boletín del museo de entomología de la Universidad del Valle 10:1-7.

Borrow C. 2011. The diversity of sequence alignment and tree space at high parameter density Doctor of Phylosophy. Imperial College London.

Carstens BC, Pelletier TA, Reid NM, and Satler JD. 2013. How to fail at species delimitation. Molecular Ecology 22:4369-4383. doi: 4310.1111/mec.12413. 10.1111/mec.12413

Dayrat B. 2005. Towards integrative taxonomy. Biological Journal of the Linnean Society 85:407-415. doi: 410.1111/j.1095-8312.2005.00503.x.

Dupuis J, Roe A, and Sperling F. 2012. Multi-locus species delimitation in closely related animals and fungi: one marker is not enough. Molecular Ecology 21:4422-4436. doi: 4410.1111/j.1365-4294X.2012.05642.x.

Eberle J, Warnock RCM, and Ahrens D. 2016. Bayesian species delimitation in Pleophylla chafers (Coleoptera) - the importance of prior choice and morphology. BMC Evolutionary Biology 16:94. doi: 10.1186/s12862-12016-10659-12863. 10.1186/s12862016-0659-3

Edgar R. 2004. MUSCLE: multiple sequence alignment with high accuracy and high throughput. Nucleic Acids Res 32:1792 - 1797.

Emlen DJ, Corley Lavine L, and Ewen-Campen B. 2007. On the origin and evolutionary diversification of beetle horns. Proceedings of the National Academy of Sciences 104:8661. doi: 8610.1073/pnas.0701209104. 10.1073/pnas.0701209104

Folmer O, Black M, Hoeh W, Lutz R, and Vrijenhoek R. 1994. DNA primers for amplification of mitochondrial cytochrome c oxidase subunit I from diverse metazoan invertebrates. Mol Mar Biol Biotechnol 3:294-299.

França FM, Korasaki V, Louzada J, and Vaz-de-Mello FZ. 2016. First report on dung beetles in intra-Amazonian savannahs in Roraima, Brazil. Biota Neotropica 16:doi: 10.1590/16760611-BN-2015-0034.

Giraldo C, Montoya S, and Escobar F. 2018. Escarabajos del estiércol en paisajes ganaderos de Colombia. Cali, Colombia: Fundación CIPAV.

Gunter NL, Weir TA, Slipinksi A, Bocak L, and Cameron SL. 2016. If dung beetles (Scarabaeidae: Scarabaeinae) arose in association with dinosaurs, did they also suffer a mass co-extinction at the K-PG boundary? PLoS ONE 11:e0153570. doi: 0153510.0151371/journal.pone.0153570. 10.1371/journal.pone.0153570

Hope F. 1838. The Coleopterist's Manual: Containing the Lamellicorn Insects of Linneus and Fabricius. London: H. G. Bohn. 
533 Jombart T. 2008. adegenet: a R package for the multivariate analysis of genetic markers.

534 Bioinformatics 24:1403-1405. doi: 1410.1093/bioinformatics/btn1129.

535

536

537

538

539

540

541

542

543

544

545

546

547

548

549

550

551

552

553

554

555

556

557

558

559

560

561

562

563

564

565

566

567

568

569

570

571

572

573

574

575

576

577

Kijimoto T, Pespeni M, Beckers O, and Moczek AP. 2013. Beetle horns and horned beetles: emerging models in developmental evolution and ecology. Developmental Biology 2:405418. doi: 410.1002/wdev.1081. 10.1002/wdev.81

Leigh J, and Bryant D. 2015. popart: full-feature software for haplotype network construction. Methods in Ecology and Evolution 6:1110-1116. doi: 1110.1111/2041-1210X.12410.

López-Guerrero I. 2005. Los Dichotomius (Coleoptera: Scarabaeidae, Dichotomiini) de la fauna de México. Boletín Sociedad Entomológica Aragonesa 36:195-209.

Louzada J, and Carvalho E Silva P. 2009. Utilisation of introduced Brazilian pastures ecosystems by native dung beetles: diversity patterns and resource use. Insect Conservation and Diversity 2:45-52. doi: 10.1111/j.1752-4598.2008.00038.x. 10.1111/j.17524598.2008.00038.x

Luederwaldt H. 1929. As espécies brasileiras do gênero Pinotus. Revista do Museu Paulista 16:603-776.

Maddison WP, and Maddison DR. 2011. Mesquite: a modular system for evolutionary analysis. 2.75 ed.

Maldaner M, Nunes R, and Vaz-De-Mello F. 2015. Taxonomic revision of the Dichotomius speciosus (Waterhouse, 1891) species group (Coleoptera: Scarabaeidae: Scarabaeinae). . Zootaxa 3986:549-560. doi: 510.11646/zootaxa.13986.11645.11642.

Martínez A. 1951. La invalidez del nombre genérico Pinotus Erichson y dos nuevas sinonímias (Col. Scarab.). Anales de la Sociedad Científica Argentina 152:138-142.

Medina CA, Lopera A, Vítolo A, and Gill B. 2001. Escarabajos coprófagos (Coleoptera: Scarabaeidae: Scarabaeinae) de Colombia. Biota Colombiana 2:131-144.

Meyer CP, and Paulay G. 2005. DNA barcoding: error rates based on comprehensive sampling. PLOS Biology 3:e422. doi: 410.1371/journal.pbio.0030422. 10.1371/journal.pbio.0030422

Monaghan MT, Inward DJG, Hunt T, and Vogler AP. 2007. A molecular phylogenetic analysis of the Scarabaeinae (dung beetles). Molecular Phylogenetics and Evolution 45:674-692. doi: 610.1016/j.ympev.2007.1006.1009. http://dx.doi.org/10.1016/j.ympev.2007.06.009

Nguyen L-T, Schmidt HA, von Haeseler A, and Minh BQ. 2015. IQ-TREE: a fast and effective stochastic algorithm for estimating Maximum-Likelihood phylogenies. Molecular Biology and Evolution 32:268-274. doi: 210.1093/molbev/msu1300.

Nichols E, Spector S, Louzada J, Larsen T, Amezquita S, and Favila ME. 2008. Ecological functions and ecosystem services provided by Scarabaeinae dung beetles. Biological Conservation 141:1461-1474. doi: 1410.1016/j.biocon.2008.1404.1011. http://dx.doi.org/10.1016/j.biocon.2008.04.011

Nunes R. 2017. Subgeneric taxonomy of Dichotomius Hope, 1838 and taxonomic revision of the subgenus Cephagonus Luederwaldt 1929 (Coleoptera: Scarabaeidae). Doctor of Phylosophy. Universidade Federal de Mato Grosso.

Nunes R, and Vaz-de-Mello F. 2013. New brachypterous species of Dichotomius Hope, with taxonomic notes in the subgenus Luederwaldtinia Martinez (Coleoptera: Scarabaeidae: Scarabaeinae). Zootaxa 3609:411-420. doi:410.11646/zootaxa.13609.11644.11643.

Nunes R, and Vaz-de-Mello F. 2016. New brachypterous species of Dichotomius (Selenocopris) Burmeister (Coleoptera: Scarabaeidae: Scarabaeinae) with the definition of species

Peer) reviewing PDF | (2019:02:35355:2:1:NEW 18 Jun 2019) 
578

579

580

581

582

583

584

585

586

587

588

589

590

591

592

593

594

595

596

597

598

599

600

601

602

603

604

605

606

607

608

609

610

611

612

613

614

615

616

617

618

619

620

621

622 groups and taxonomic notes in the subgenus. . Zootaxa 4139:76-92. doi:

10.11646/zootaxa.14139.11641.11644.

Nunes VL, Beaumont MA, Butlin RK, and Paulo OS. 2012. Challenges and pitfalls in the characterization of anonymous outlier AFLP markers in non-model species: lessons from an ocellated lizard genome scan. Heredity 109:340-348. doi:310.1038/hdy.2012.1048. http://www.nature.com/hdy/journal/v109/n6/suppinfo/hdy201248s1.html

Olave M, Avila LJ, Sites JW, and Morando M. 2017. Hidden diversity within the lizard genus Liolaemus: genetic vs morphological divergence in the L. rothi complex (Squamata:Liolaeminae). Molecular Phylogenetics and Evolution 107:56-63. doi: 10.1016/j.ympev.2016.1009.1009. https://doi.org/10.1016/j.ympev.2016.09.009

Padial J, and De La Riva I. 2010. A response to recent proposals for integrative taxonomy. Biological Journal of the Linnean Society 101:747-756. doi: 710.1111/j.10958312.2010.01528.x.

Petit RJ, and Excoffier L. 2009. Gene flow and species delimitation. Trends in Ecology \& Evolution 24:386-393. doi: 310.1016/j.tree.2009.1002.1011. https://doi.org/10.1016/j.tree.2009.02.011

Philips K. 2011. The evolutionary history and diversification of dung beetles. In: Simmons L, and Ridsdill-Smith J, eds. Ecology and evolution of dung beetles. Oxford, UK: Blackwell Publishing, 21-45.

Rohlf JF. 2004. TpsDig, Program for digitizing landmarks and outlines for geometric morphometric analyses. Stony Brook, NY: Department of Ecology and Evolution, State University of New York.

Rozas J, Sanchez-DelBarrio JC, Messeguer X, and Rozas R. 2003. DnaSP, DNA polymorphism analyses by the coalescent and other methods. Bioinformatics 19:2496-2497. doi: 2410.1093/bioinformatics/btg2359.

Sarmiento-Garcés R, and Amat-García G. 2014. Escarabajos del género Dichotomius Hope 1838 (Scarabaeidae: Scarabaeinae) en Colombia: Universidad Nacional de Colombia.

Schlick-Steiner B, Steiner F, Seifert B, Stauffer C, Christian E, and Crozier R. 2009. Integrative taxonomy: a multisource approach to exploring biodiversity. Annual Review of Entomology 55:421-438. doi: 410.1146/annurev-ento-112408-085432.

Schoolmeesters P. 2019. Scarabs: World Scarabaeidae Database (version Jan 2016). . Available at http://www.catalogueoflife.org/annual-checklist/2016.

Schwarzfeld M, and Sperling F. 2014. Species delimitation using morphology, morphometrics, and molecules: definition of the Ophion scutellaris Thomson species group, with descriptions of six new species (Hymenoptera, Ichneumonidae). Zookeys 59:114. doi: 110.3897/zookeys.3462.8229.

Scrucca L, Fop M, Murphy T, and Raftery A. 2016. mclust 5: clustering, classification and density estimation using Gaussian finite mixture models. The R journal 8:289-317.

Simmons LW, and Watson NL. 2010. Mate choice in the dung beetle Onthophagus sagittarius: are female horns ornaments? Behavioral Ecology 21:424-430. doi: 410.1093/beheco/arp1207.

Simon C, Frati F, Beckenbach A, Crespi B, and Liu H. 1994. Evolution, weighting, and phylogenetic utility of mitochondrial gene sequences and a compilation of conserved polymerase chain reaction primers. Annals of the Entomological Society of America 87:651-701. doi: 610.1093/aesa/1087.1096.1651. 
623 Solís-Lemus C, Knowles L, and Ané C. 2014. Bayesian species delimitation combining multiple

624

625

626

627

628

629

630

631

632

633

634

635

636

637

638

639

640

641

642

643

644

645

646

647

648

649

650 genes and traits in a unified framework. . Evolution 69:492-507. doi: 410.1111/evo.12582.

Sturaro M, Rodrigues M, Colli G, Knowles L, and Avila-Pires T. 2018. Integrative taxonomy of the lizards Cercosaura ocellata species complex (Reptilia: Gymnophthalmidae). Zoologischer Anzeiger - A Journal of Comparative Zoology 275: 37-65. doi: 10.1016/j.jcz.2018.1004.1004.

Sukumaran J, and Knowles LL. 2017. Multispecies coalescent delimits structure, not species. Proceedings of the National Academy of Sciences 114:1607. doi: 1610.1073/pnas.1607921114. 10.1073/pnas.1607921114

Tarasov S, and Dimitrov D. 2016. Multigene phylogenetic analysis redefines dung beetles relationships and classification (Coleoptera: Scarabaeidae: Scarabaeinae). BMC Evolutionary Biology 16:257. doi: 210.1186/s12862-12016-10822-x. 10.1186/s12862016-0822-X

Tarasov S, and Génier F. 2015. Innovative bayesian and parsimony phylogeny of dung beetles (Coleoptera, Scarabaeidae, Scarabaeinae) enhanced by ontology-based partitioning of morphological characters. PLoS ONE 10:e0116671. doi: 0116610.0111371/journal.pone.0116671. 10.1371/journal.pone.0116671

Vaz-de-Mello F, Edmonds W, Ocampo F, and Schoolmeesters P. 2011. A multilingual key to the genera and subgenera of the subfamily Scarabaeinae of the New World (Coleoptera: Scarabaeidae). Zootaxa 2854:1-73.

Vulinec K. 1999 Dung beetles, monkeys and seed dispersal in the Brazilian Amazon Doctor of Phylosophy. University of Florida.

Yang L, Kong H, Huang J-P, and Kang M. 2019. Different species or genetically divergent populations? Integrative species delimitation of the Primulina hochiensis complex from isolated karst habitats. Molecular Phylogenetics and Evolution 132:219-231. doi: 210.1016/j.ympev.2018.1012.1011. https://doi.org/10.1016/j.ympev.2018.12.011 


\section{Table $\mathbf{1}$ (on next page)}

Genetic diversity indices for all species and for $D$. satanas

ND: Non-different from zero. *Significance $<0.05$ 
1 Table 1. Genetic diversity indices for all species and for D. satanas

\begin{tabular}{llccccc}
\hline Gen & & $\begin{array}{c}\text { Number of } \\
\text { haplotypes } \\
(\mathbf{H})\end{array}$ & $\begin{array}{c}\text { Haplotype } \\
\text { diversity }\end{array}$ & $\begin{array}{c}\text { Nucleotide } \\
\text { diversity }(\boldsymbol{\pi})\end{array}$ & $\begin{array}{c}\text { Substitution } \\
\text { rate }(\boldsymbol{\theta})\end{array}$ & Tajima's D \\
\hline \multirow{2}{*}{$\mathrm{COI}$} & D. satanas & 29 & 0.95 & 0.02875 & 0.02455 & 0.4089 (ND) \\
& All species & 74 & 0.98 & 0.07645 & 0.06515 & $0.6996(\mathrm{ND})$ \\
\multirow{2}{*}{$28 \mathrm{~S}$} & $\begin{array}{l}\text { D. satanas } \\
\text { All species }\end{array}$ & 3 & 0.59 & 0.00248 & 0.00229 & $0.268(\mathrm{ND})$ \\
\hline
\end{tabular}

2 ND: Non-different from zero. *Significance $<0.05$

3

4 


\section{Table 2 (on next page)}

Population differentiation among populations of $D$. satanas

WC: Western Cordillera; CC: Central Cordillera; EC: Eastern Cordillera. Central America was not included because its sequences were only available for one fragment. NA: not computable. ${ }^{* *} 0.001<p<0.01 ; * * * p<0.001$ 
1 Table 2. Summary statistics of population differentiation among populations of $D$. satanas.

\begin{tabular}{lccccccccc}
\hline & \multicolumn{3}{c}{ WC - CC } & \multicolumn{3}{c}{ WC - EC } & \multicolumn{2}{c}{ CC - EC } \\
\cline { 2 - 9 } & $\mathbf{N}_{\mathbf{S T}}$ & $\mathbf{D}_{\mathbf{X Y}}$ & $\mathbf{D}_{\mathbf{a}}$ & $\mathbf{N}_{\mathbf{S T}}$ & $\mathbf{D}_{\mathbf{X Y}}$ & $\mathbf{D}_{\mathbf{a}}$ & $\mathbf{N}_{\mathbf{S T}}$ & $\mathbf{D}_{\mathbf{X Y}}$ & $\mathbf{D}_{\mathbf{a}}$ \\
\hline COI & $0.34^{* *}$ & 0.04269 & 0.02173 & $0.19^{* *}$ & 0.04810 & 0.01000 & $0.51 * *$ & 0.03199 & 0.01536 \\
$\mathbf{2 8 S}$ & $\mathrm{NA}$ & 0.000001 & 0.000001 & $0.66^{* *}$ & 0.00332 & 0.00218 & $0.56^{* *}$ & 0.00382 & 0.00214 \\
\hline
\end{tabular}

2 WC: Western Cordillera; CC: Central Cordillera; EC: Eastern Cordillera. Central America was not included because its sequences

3 were only available for one fragment. NA: not computable. $* * 0.001<\mathrm{p}<0.01 ; * * * \mathrm{p}<0.001$ 


\section{Figure 1}

Shape variation of the aedeagus in 28 species of Dichotomius

(a) Principal Component Analysis (PCA). Deformation grids showing the maximum (b) and minimum (c) shape change of the aedeagus associated with PC1. Deformation grids showing the maximum (d) and minimum (e) shape change of the aedeagus associated with PC2. (f) Scatter plot of the DAPC analysis with species identity as prior information; ellipses correspond to the $95 \%$ confidence interval around the centroid. (g) Model based clustering showing the best fitting cluster model by BIC reassignment probabilities to the clusters with individuals ordered by cluster; bars below represent the reassignment probabilities to the clusters with individuals ordered by cluster and by a priori defined morphospecies. (ag: agenor; al: alyattes; am: amicitiae; an: andresi; ba: batesi; be: belus; bo: boreus; co: coenosus; com: compresicollis; cos: costaricensis; de: deyrrollei; di: divergens; fa: favi; fo: fonsecae; fr: fortestriatus; in: inachus; ma: mamillatus; ni: nisus; oh: ohausi; po: podalirius; pr: protectus; qu: quinquedens; qui: quinquelobatus; ri: riberoi; ro: robustus; sa: satanas; wo: worontzowi; yu: yucatanus). 
a.

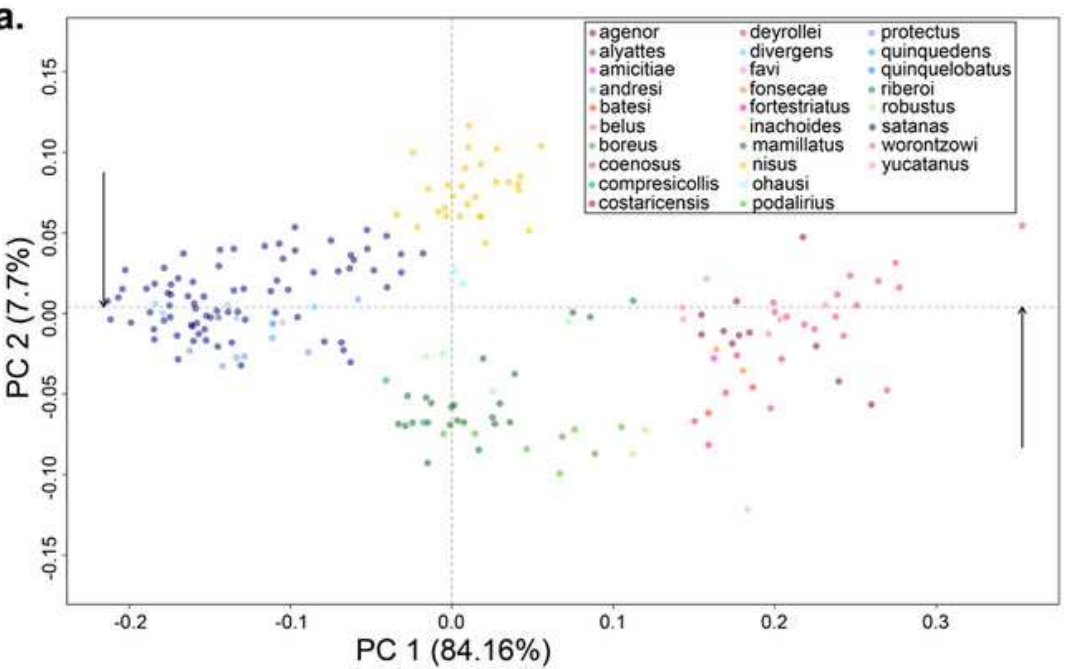

f.

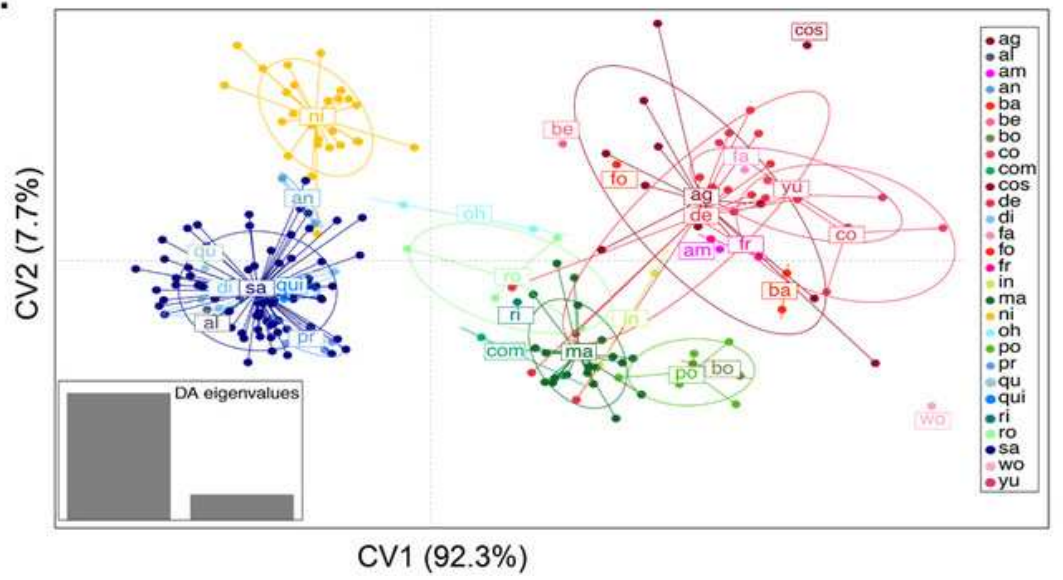

b.

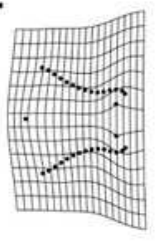

d.

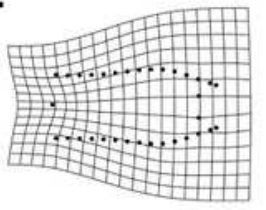

e.
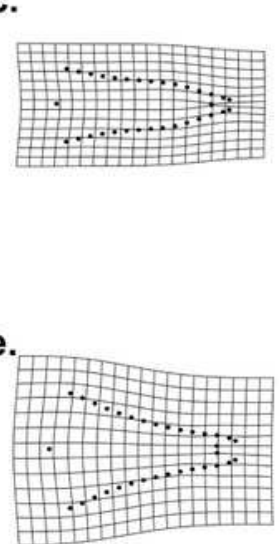

\section{g.}

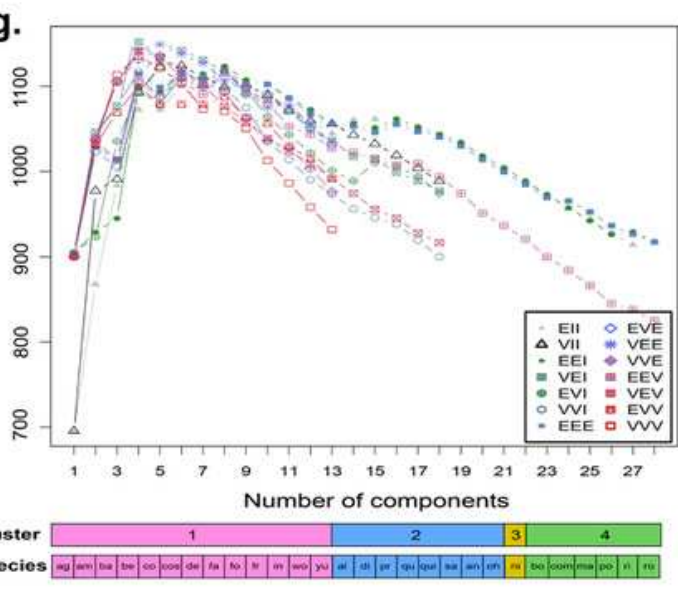




\section{Figure 2}

\section{Phylogenetic relationships of Dichotomius species}

Summary phylogeny based on the ML tree of 16 species of Dichotomius and nine outgroup species (full phylogeny is shown in Fig. S5). Next to the species name we indicate the number of individuals within each collapsed branch (N), subgenus (SBG) and species group (SPG). Squares mapped onto branches indicate habitat/ecosystem. Circles on nodes indicate bootstrap support. Deepest clades are numbered as 1 and 2 as a reference in the main text.

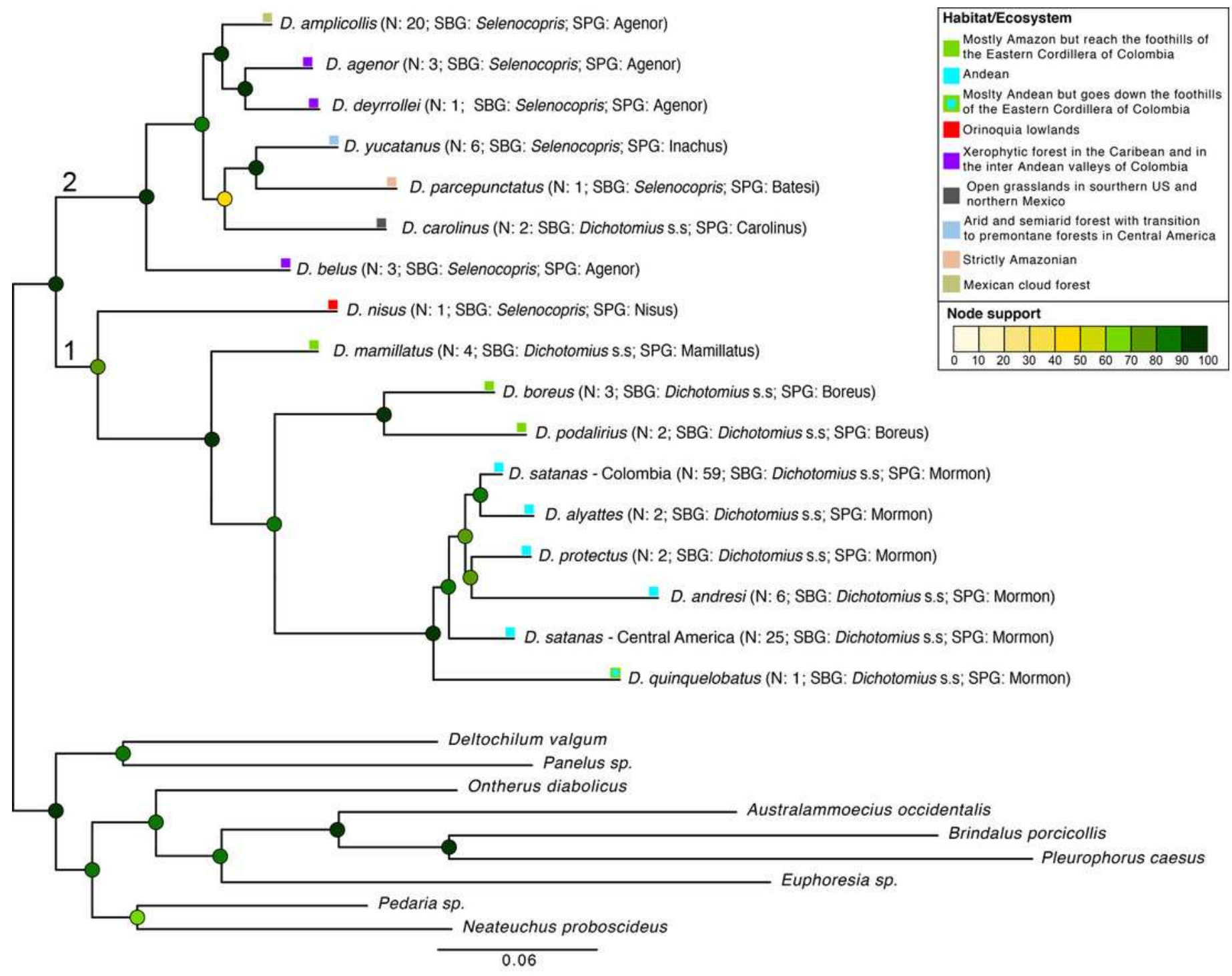




\section{Figure 3}

Phylogenetic relationships and phenotype variation in Colombian populations of Dichotomius satanas

(a) ML tree based on the concatenation of the $\mathrm{COI}$ and $28 \mathrm{~S}$ genes. Circles on nodes indicate bootstrap support. Coloured squares highlight geographic clusters and are connected to the collecting localities in Colombia. (b, $\mathbf{c}$ and $\mathbf{d}$ ) Photos show the phenotype of males (M) and females, that can either have two (F2) or four (F4) protuberances in the pronotum. 
a.

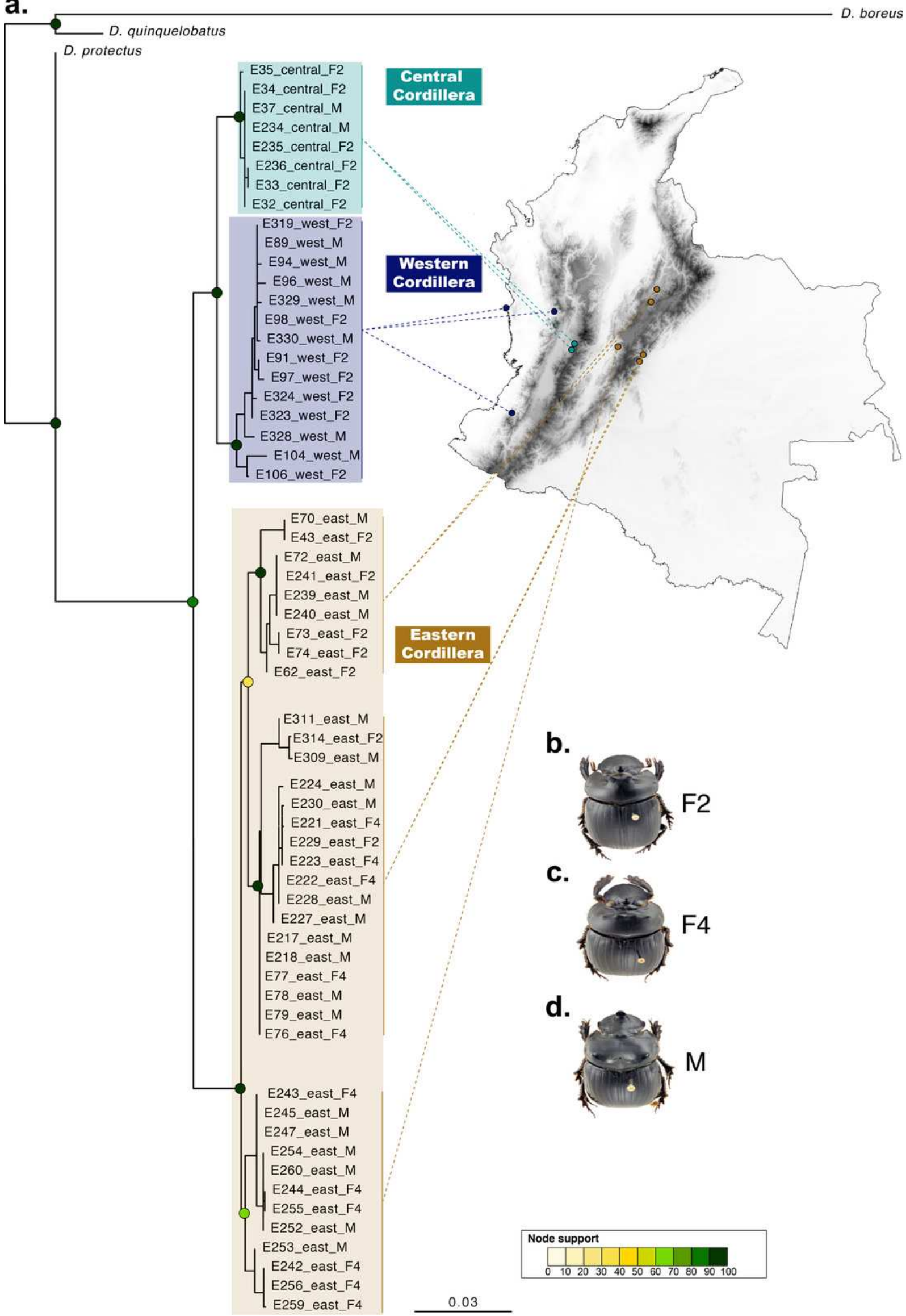




\section{Figure 4}

\section{Total-evidence Bayesian species delimitation}

Mean posterior probabilities of Bayesian species delimitations were inferred under 9 different theta and tau prior combinations. The posterior probability of each of these combinations is colour-coded and indicated in $3 \times 3$ boxes on each node of the guide tree. The large $3 \times 3$ inset indicate the position of each prior combination in these boxes. Next to the species name we indicate the number of individuals included per species in the analysis (Nmol: number of individuals with molecular data, Nmor: number of individuals with morphological data). Subgenus (SBG) and species group (SPG) are also indicated. Deepest clades are numbered as 1 and 2 as a reference in the main text

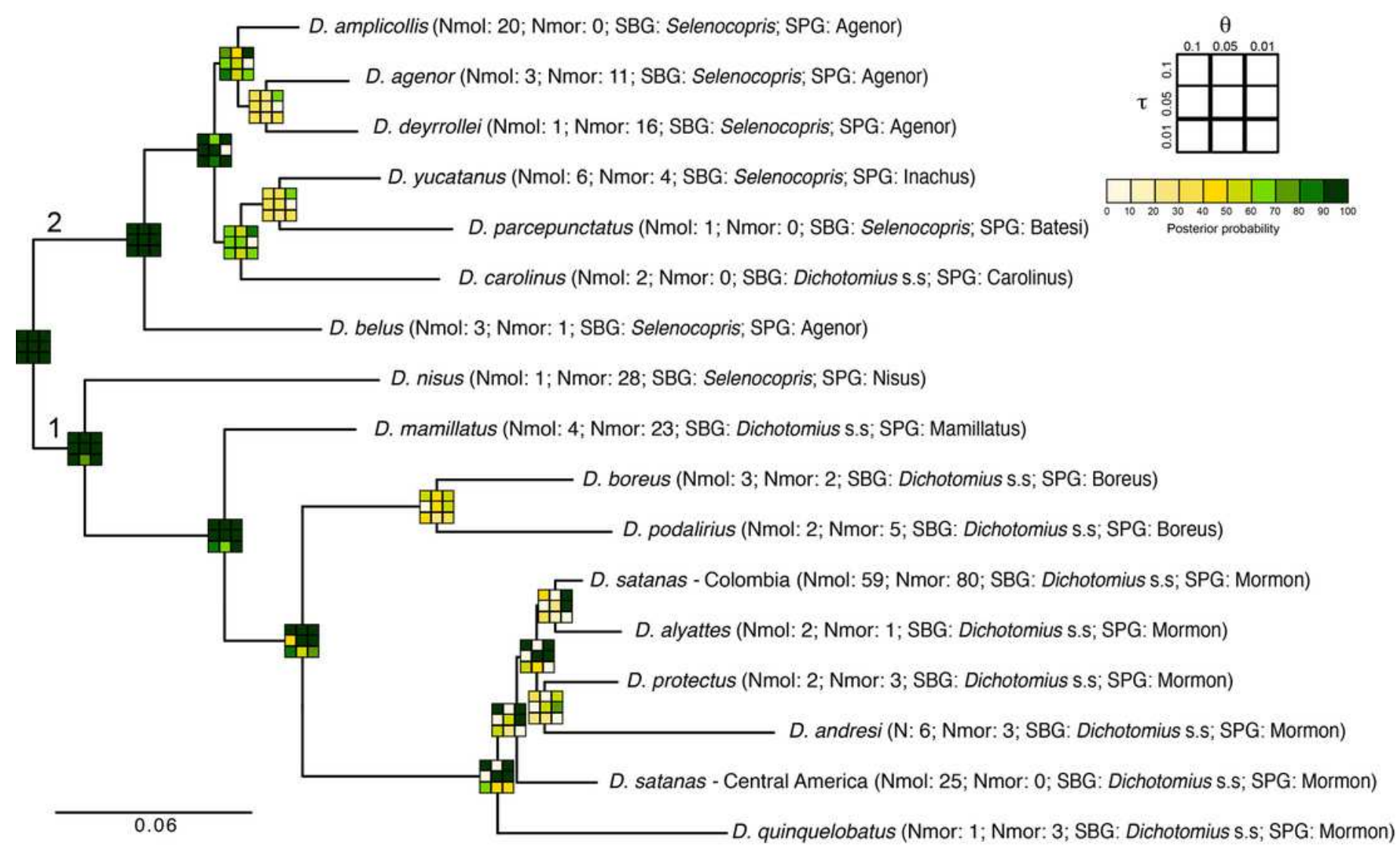

